\title{
CHEMOSPHERE
}

\section{Degradation of aqueous carbon tetrachloride by nanoscale zerovalent copper on a cation resin}

\author{
Chin Jung Lin *, Shang-Lien Lo, Ya Hsuan Liou \\ Research Center for Environmental Pollution Prevention and Control Technology, Graduate Institute of Environmental Engineering, \\ National Taiwan University, 71 Chou-Shan Road, Taipei 106, Taiwan, ROC
}

Received 18 December 2003; received in revised form 23 November 2004; accepted 23 November 2004

\begin{abstract}
Nanoscale zerovalent copper supported on a cation resin was successfully synthesized to enhance the removal of carbon tetrachloride $\left(\mathrm{CCl}_{4}\right)$ from contaminated water. The use of the cation resin as a support prevents the reduction of surface area due to agglomeration of nanoscale zerovalent copper particles. Moreover, the cation resin recycles the copper ions resulting from the reaction between $\mathrm{CCl}_{4}$ and $\mathrm{Cu}^{0}$ by simultaneous ion exchange. The decline in the amount of $\mathrm{CCl}_{4}$ in aqueous solution results from the combined effects of degradation by nanoscale zerovalent copper and sorption by the cation resin; thus the amount of $\mathrm{CCl}_{4}$ both in aqueous solution and sorbed onto the resin were measured. The pseudo-first-order rate constant normalized by the surface-area and the mass concentration of nanoscale zerovalent copper $\left(k_{\mathrm{SA}}\right)$ was $2.1 \pm 0.1 \times 10^{-2} \mathrm{lh}^{-1} \mathrm{~m}^{-2}$, approximately twenty times that of commercial powdered zerovalent copper $(0.04 \mathrm{~mm})$. Due to the exchange between $\mathrm{Cu}^{2+}$ and the strongly acidic ions $\left(\mathrm{H}^{+}\right.$or $\left.\mathrm{Na}^{+}\right)$, the $\mathrm{pH}$ was between 3 and 4 in unbuffered solution and $\mathrm{Cu}^{2+}$ at the concentration of less than $0.1 \mathrm{mg} \mathrm{l}^{-1}$ was measured after the dechlorination reaction. In the above-ground application, resin as a support would facilitate the development of a process that could be designed for convenient emplacement and regeneration of porous reductive medium.
\end{abstract}

(c) 2004 Elsevier Ltd. All rights reserved.

Keywords: Nanoscale; Zerovalent metal; Copper; Dechlorination; Carbon tetrachloride

\section{Introduction}

Chlorinated aliphatic organic compounds, particularly containing one to three carbon atoms, such as carbon tetrachloride $\left(\mathrm{CCl}_{4}\right)$, trichloroethylene (TCE), and tetrachloroethylene (PCE), are widely used as industrial solvents in degreasing, washing, extraction, foaming, spraying, and manufacturing (Muftikian et al., 1995; Cheng and $\mathrm{Wu}, 2000)$. Improper use and disposal of

\footnotetext{
* Corresponding author. Tel.: +8862 23625373; fax: +8862 23928821.

E-mail address: d89541005@ntu.edu.tw (C.J. Lin).
}

these solvents has resulted in wide-spread occurrence in groundwater. In recent years, treatment of aqueous solution containing chlorinated solvents has attracted much attention. Conventional physicochemical methods accompanying the use of expensive chemicals or high energies largely restrict application at the field scale. Biological processes may be effective, but conditions must be well controlled to enable microorganisms to grow. Thus, it may not always be practical. Phytoremediation, using the ability of plants to remove and degrade chlorinated solvents, may offer a cost-effective, in situ, and safe alternative to conventional physicochemical methods (McCutcheon and Schnoor, 2003). 
The use of zerovalent metals as reductants to degrade chlorinated organic compounds is cost-effective and effectively reduces the concentration of target contaminants (Gillham and O'Hannesin, 1994; Matheson and Tratnydk, 1994; Agrawal and Tratnyek, 1996; Orth and Gillham, 1996; Gu et al., 1999; Phillips et al., 2000). Being inexpensive and benign in environment, zerovalent iron $\left(\mathrm{Fe}^{0}\right)$ is the most applied reactive metal; the potential for reducing more complex anthropogenic chemicals such as pentachlorophenol (Kim and Carraway, 2000), pesticides (Sayles et al., 1997; Eykholt and Davenport, 1998) and azo dyes (Nam and Tratnyek, 2000) has been demonstrated in the past few years. Recently, however, several drawbacks associated with the reaction between $\mathrm{Fe}^{0}$ and chlorinated organics included (1) as the reaction proceeds, the $\mathrm{pH}$ in the reaction zone slightly rises (Matheson and Tratnydk, 1994; Phillips et al., 2000; Doong et al., 2003), caused by the net result of a number of chemical processes including iron corrosion and subsequent precipitation of ferrous iron $(\mathrm{Su}$ and Puls, 2004). At elevated $\mathrm{pH}$, the precipitation of iron hydroxides and iron carbonates form and decrease reactivity by reducing the exposure of the iron surface to aqueous solution (Chen et al., 2001). The media can become plugged and cemented into pipes. (2) High concentration of iron ions, coming from several oxidation reactions, in the effluent of a above-ground reactor leads to the sludge disposal and treatment at additional cost and the potential blocking of pipes of the treatment system. (3) The difficulty and frequent replacement or the chemical reconditioning of the massive iron particles in the above-ground reactor results in higher costs.

The available surface area of iron is the most important factor that governs the reduction rate. Studies have demonstrated the reductive degradation rates for several target compounds are proportional to the total surface area of iron (Matheson and Tratnydk, 1994; Agrawal and Tratnyek, 1996; Siantar et al., 1996; Huang et al., 1998; Su and Puls, 1999). A nanoparticle is conventionally defined as the diameter of a particle in the 1-100 nm range (Klabunde, 2001). Reducing the particle size of an equivalent mass of $\mathrm{Fe}^{0}$ into the nanoscale range sharply increases reactivity (Boronina et al., 1995; Wang and Zhang, 1997; Choe et al., 2000). Zhang et al. (1998) reported that the surface-area-normalized rate constant of the reaction between nanoscale $\mathrm{Fe}^{0}$ and TCE or $\mathrm{CCl}_{4}$ can be increased by a factor of 10-100 compared to commercial $\mathrm{Fe}^{0}$ powder $(<10 \mu \mathrm{m})$. The dramatically increased reactivity results from a higher ratio of surface area to volume of nanoscale $\mathrm{Fe}^{0}$, higher levels of stepped surface (stepped surface is also known as high Miller index which usually has a step structure), and higher surface energies compared to powdered $\mathrm{Fe}^{0}$ (Zhang et al., 1998). Nanoscale $\mathrm{Fe}^{0}$ particle suspensions can be applied in an above-ground treatment reactor or directly injected into contaminated aquifers. However, the critical obstacles in the application of nanoscale $\mathrm{Fe}^{0}$ to reduce chlorinated solvents are (1) the immediate oxidation in air or water due to the active surface of nanoscale $\mathrm{Fe}^{0}$, (2) immediate agglomeration into micrometer particles due to the tendency to reduce the high surface energies, and (3) difficulty in separating such small particles from the effluent of the above-ground reactor when nonmagnetic iron oxides such as goethite and hematite form.

Use of a support medium to stabilize and isolate a metal particle avoids some problems with nanoscale particles (Ziolo et al., 1992). In this study, attachment to a commercial cation resin not only prevents nanoscale zerovalent metal agglomeration but also recycles metal ions (the product of the dechlorination reaction) by simultaneous ion exchange. Furthermore, attachment to a fixed medium prevents metal ions from being washed out of the treatment system. Moreover, acidic cation resins release $\mathrm{H}^{+}$or $\mathrm{Na}^{+}$to exchange equivalent metal ions and cause acidic conditions which can inhibit precipitation of metal salts. The polymer matrix is also light and easily deformable. The concept for the use of nanoscale zerovalent metal coated resin mesh in an above-ground reactor and the reactions are shown in Fig. 1.

In this work, zerovalent copper was chosen as an electron donor to degrade $\mathrm{CCl}_{4}$. The use of copper as a reductant was preferred due to (1) the reliable in situ measurement of the surface area of resin-supported copper particles by temperature-programmed reduction (TPR) has been demonstrated (Grift et al., 1991), and (2) nanoscale zero valent copper exhibits relative stability in water, avoiding undesired competitive reactions. Based on these reasons, this study compared the deholgenation kinetics of nanoscale and powdered copper particles. This study also evaluated feasibility of using reductive nanoscale zerovalent metal coated resin to degrade chlorinated organics in an above-ground reactor.

\section{Experimental section}

\subsection{Chemicals}

All aqueous solutions were made in water purified with a Milli-Q system $(18.2 \mathrm{M} \Omega / \mathrm{cm})$. High-pressure liquid chromatography grade carbon tetrachloride, chloroform, and dichloromethane were obtained from Aldrich (USA). Copper (II) nitrate trihydrate was from Alfa (USA). Copper powder was obtained from Riedelde Haen $(\approx 0.04 \mathrm{~mm},>99.5 \%$, GR grade, USA).

\subsection{Preparation of nanoscale $\mathrm{Cu}$ coated resin}

The polymer matrix used in this study is a commercial ion-exchange resin manufactured by Dow Chemical 


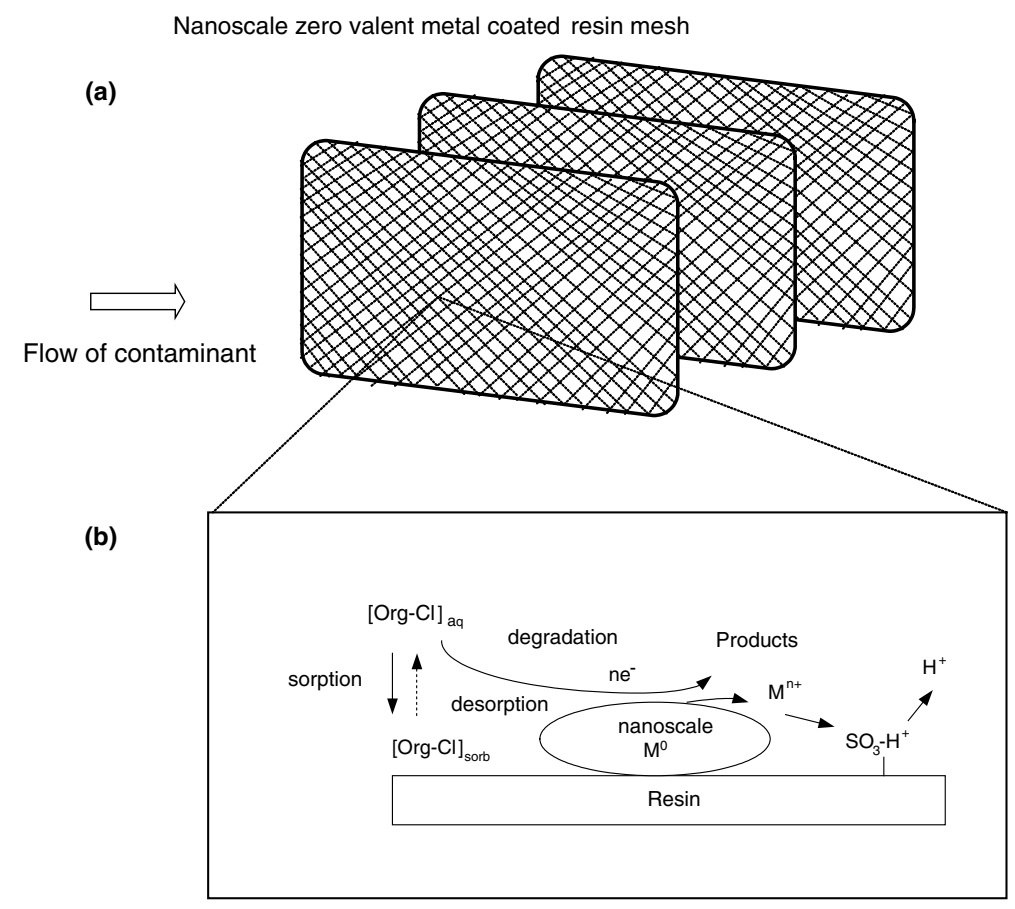

Fig. 1. Nanoscale zerovalent copper coated resin mesh application in an above-ground reactor and the reactions.

Company (USA) and marketed under the trade name Dowex ${ }^{\mathrm{TM}}$. The sulfonated polystyrene matrix is composed of spheres with diameters of $30-60 \mu \mathrm{m}$. The resin was first loaded with the desired concentration of $\mathrm{Cu}^{2+}$ from an aqueous solution of $\mathrm{Cu}\left(\mathrm{NO}_{3}\right)_{2} \cdot 3 \mathrm{H}_{2} \mathrm{O}$, followed by thorough washing to remove excess physisorbed copper ions. After washing, the fresh samples were dried in air at $120{ }^{\circ} \mathrm{C}$ for $18 \mathrm{~h}$. The dried samples were then reduced under a flow of $\mathrm{H}_{2}$ and $\mathrm{N}_{2}$ gas (20 vol\%, $100 \mathrm{ml} \mathrm{min}^{-1}$ ). During the reduction, the temperature was increased from ambient to $300{ }^{\circ} \mathrm{C}$ at a rate of $10^{\circ} \mathrm{C} \mathrm{min}{ }^{-1}$ and then maintained at $300{ }^{\circ} \mathrm{C}$ for $3 \mathrm{~h}$. The samples were finally cooled to room temperature in the reducing gas atmosphere.

\subsection{Characterization of nanoscale $C u^{0}$ coated resin}

TPR was used to study the required reduction temperature with the apparatus similar to one described previously (Bond and Namijo, 1989). The fresh sample of $\mathrm{Cu}^{2+}$ on the resin was dried in air at $120^{\circ} \mathrm{C}$ for $18 \mathrm{~h}$. Then, the resin was heated in a flow of $\mathrm{He}\left(50 \mathrm{ml} \mathrm{min}^{-1}\right)$ from room temperature to $250{ }^{\circ} \mathrm{C}$ at $10^{\circ} \mathrm{C} \mathrm{min}{ }^{-1}$, then maintained at $250{ }^{\circ} \mathrm{C}$ for $30 \mathrm{~min}$ to remove the volatiles. A flow of $\mathrm{H}_{2}$ and $\mathrm{N}_{2}$ gas (20 vol\%, $100 \mathrm{ml} \mathrm{min}^{-1}$, Hoekloos (Netherlands)) was used as the reducing gas. The oven temperature was programmed to rise from ambient to $350{ }^{\circ} \mathrm{C}$ at $10^{\circ} \mathrm{C} \mathrm{min}{ }^{-1}$ and then staying at $350{ }^{\circ} \mathrm{C}$ for $1 \mathrm{~h}$.
The oxidation states of copper on the resin were identified by electron spectroscopy for chemical analysis (ESCA). The ESCA measurements were perform by using a Vacuum Generators ECSALAB MKП photoelectron spectrometer (East Grinsted, UK) with an ALK $\alpha 1,2$ (1486.6 eV) X-ray source and a hemispherical $150 \mathrm{~mm}$ mean radius electron analyzer with a take-off angle of $90^{\circ}$. During the data acquisition, the pressure in the sample chamber did not exceed $6.7 \times 10^{-8} \mathrm{~Pa}$.

The morphology and size of the resulting nanoscale $\mathrm{Cu}^{0}$ coated resin was viewed with a transmission electron microscopy. The localized elemental information from the chose region was determined with energy disperse X-ray spectroscopy (EDX) in conjunction with electron microscopy.

\subsection{Surface area of attached copper particles}

As described by Grift et al. (1991), the determination of the surface area of attached copper particles is based on the measurement of hydrogen consumption after surface oxidation of the copper by $\mathrm{N}_{2} \mathrm{O}$.

$2 \mathrm{Cu}+\mathrm{N}_{2} \mathrm{O} \rightarrow \mathrm{Cu}_{2} \mathrm{O}+\mathrm{N}_{2}$ (copper surface atoms only)

$\mathrm{Cu}_{2} \mathrm{O}+\mathrm{H}_{2} \rightarrow 2 \mathrm{Cu}+\mathrm{H}_{2} \mathrm{O}$

According to the surface oxidation measurements using $\mathrm{N}_{2} \mathrm{O}$ at various temperatures (Evans et al., 1983), the 
average site density is $1.4 \times 10^{19} \mathrm{Cu}$-atoms $\mathrm{m}^{-2}$. Compared to the area of the thermal conductivity detector signals for $1 \mathrm{ml} \mathrm{H}_{2}\left(40.9 \mu \mathrm{mol}\right.$ at $\left.1 \mathrm{~atm}, 25^{\circ} \mathrm{C}\right)$ undergoing temperature programmed reduction $\left(A_{1 \mathrm{ml}, \mathrm{H}_{2}}\right)$, the $\mathrm{H}_{2}$ consumption of various copper ions on the resin undergoing temperature programmed reduction was obtained. The numbers of copper atoms at the surface $\left(N_{\mathrm{surf}, \mathrm{Cu}}\right)$ were calculated from the stoichiometry of Eq. (2).

$N_{\text {surf }, \mathrm{Cu}}=\frac{A_{\text {surf }, \mathrm{Cu}}}{A_{1 \mathrm{ml}, \mathrm{H}_{2}}} \times 40.9 \times 10^{-6} \times N_{\mathrm{s}}(\mathrm{mol})$

where $A_{\text {surf,Cu }}$ is the area of the thermal conductivity detector signal for the second TPR, and $N_{\mathrm{s}}$ is 2 from the stoichiometry of Eq. (2). Copper surface area $\left(S_{\mathrm{Cu}}\right)$ on the resin is

$S_{\mathrm{Cu}}=\frac{\left(N_{\text {surf }, \mathrm{Cu}} \times N_{\mathrm{av}} \times \frac{1}{1.4 \times 10^{19}}\right)}{W_{\text {resin }}}\left(\mathrm{m}^{2} \mathrm{Cug}_{\text {-resin }}{ }^{-1}\right)$

where $N_{\text {av }}$ is Avogadro constant $\left(6.023 \times 10^{23} \mathrm{~mol}^{-1}\right)$, and $W_{\text {resin }}$ is the mass $(\mathrm{g})$ of the resin.

\subsection{Reactor system}

All dynamic experiments were performed for the degradation and sorption of $\mathrm{CCl}_{4}$ by $\mathrm{Cu}^{0}$ coated resin in a closed batch system with zero headspace (initial $\mathrm{pH}=7.1-7.3)$. In these systems, the desired amount of $\mathrm{Cu}^{0}$ coated resin was added into a $15 \mathrm{ml}$ amber serum vial, sequentially filled up with Ar-purged unbuffered Milli- $\mathrm{Q}^{\mathrm{TM}}$ water. A $100 \mu \mathrm{l}$ aliquot of $\mathrm{CCl}_{4}\left(700 \mathrm{mg} \mathrm{l}^{-1}\right)$ was then added under the water surface. Immediately after $\mathrm{CCl}_{4}$ addition, the vials were capped with Teflon silicone septa and aluminum seals and then mixed on a rotary shaker $(50 \mathrm{rmp})$ at room temperature $\left(24 \pm 1^{\circ} \mathrm{C}\right)$ in the dark.

\subsection{Extraction and analysis}

Aqueous phase and total system concentration of $\mathrm{CCl}_{4}$ were determined by liquid-liquid and liquid-solid extraction using $n$-hexane as a solvent. The sampling method and extraction process was similar to the method reported by Burris et al. (1995). There are two stages to extract $\mathrm{CCl}_{4}$ from residual aqueous phase and sorbed phase on the resin. Firstly, $5 \mathrm{ml}$ of aqueous solution was collected from the amber serum vial by a gas-tight syringe through the septa, and simultaneously another disposable needle was used to inject $13 \mathrm{ml}$ of helium to replace the liquid removed. Liquid-liquid extraction of the sample was performed with $5 \mathrm{ml} n$-hexane by axial rotation on a roller drum at $10 \mathrm{rpm}$, at room temperature, and in the dark for $30 \mathrm{~min}$. The successive withdrawal of $8 \mathrm{ml}$ of solution using the second gas-tight syringe was discarded. Secondly, another syringe of $5 \mathrm{ml}$ $n$-hexane was spiked to the same vial to extract $\mathrm{CCl}_{4}$ from residual aqueous solution and the resin by axial rotation on a roller drum under the conditions described above. Two separate $0.5 \mathrm{ml}$ samples of the liquid-liquid and the liquid-solid extractions were measured using a HP5890 GC equipped with a DB-624 capillary column and an electron capture detector operated in the splitless mode. Temperature conditions were programmed as follows: oven temperature at $40^{\circ} \mathrm{C}$; injection port temperature at $180{ }^{\circ} \mathrm{C}$; detector temperature at $300^{\circ} \mathrm{C}$. Ultrapure nitrogen was the $\mathrm{GC}$ carrier gas at a flow rate of $4.16 \mathrm{ml} \mathrm{min}{ }^{-1}$. Peaks were quantified by comparing retention time and peak areas with standards. The total $\mathrm{CCl}_{4}$ mass $\left(\mathrm{mg} \mathrm{vial}^{-1}\right)$ come from the sum of both the measured masses in the liquid-liquid and the liquidsolid extractions. The sorbed $\mathrm{CCl}_{4}$ concentration on re$\sin \left(C_{\mathrm{s}}, \mu \mathrm{g}-\mathrm{CCl}_{4} \mathrm{~g}_{\text {-resin }}{ }^{-1}\right)$ was determined by the difference of total and aqueous $\mathrm{CCl}_{4}$ mass (Burris et al., 1995) as follows:

$C_{\mathrm{s}}=\frac{C_{\mathrm{T}}-\left(C_{\mathrm{w}} \times V_{\mathrm{w}}\right)}{m_{\mathrm{s}}}$

where $C_{\mathrm{T}}$ denotes the total mass, $C_{\mathrm{w}}$ is the aqueous phase concentration, $V_{\mathrm{w}}$ is the volume of aqueous solution, and $m_{\mathrm{s}}$ is the mass of the added resin. All experiments were duplicated or triplicated.

The $\mathrm{pH}$ was measured with a Beckman Model $71 \mathrm{pH}$ meter. The concentration of copper ions in aqueous solution was determined by an atomic absorption spectrophotometry (PerkinElmer AAnalyst $800^{\mathrm{TM}}$ ). Chloride was analyzed using an ion chromatograph (Dionex DX-100 ${ }^{\mathrm{TM}}$ ).

\section{Results and discussion}

\subsection{Reduction temperature}

The temperature programmed reduction of $\mathrm{Cu}^{2+}$ on the resin in a flow of $\mathrm{H}_{2}$ and $\operatorname{Ar}(20 \mathrm{vol} \%$, $60 \mathrm{ml} \mathrm{min}{ }^{-1}$ ) indicated two peaks of hydrogen consumption between 270 and $280^{\circ} \mathrm{C}$, and between 300 and $320^{\circ} \mathrm{C}$ (Fig. 2). These peaks correspond to the reduction of $\mathrm{Cu}^{2+}$ to $\mathrm{Cu}^{+}$and the reduction of $\mathrm{Cu}^{+}$ to zerovalent copper. After a dried sample of $\mathrm{Cu}^{2+}$ on the resin was reduced in a flow of $\mathrm{H}_{2}$ and $\mathrm{N}_{2}$ gas $\left(20 \mathrm{vol} \%, 50 \mathrm{ml} \mathrm{min}^{-1}\right)$ at $300^{\circ} \mathrm{C}$ for $3 \mathrm{~h}$, all copper on the resin was reduced to zerovalence. Fig. 3 shows that only zerovalent copper remained. Thus, this ESCA established that the temperature was high enough to ensure complete reduction. Compared to the common aqueous-phase reduction with $\mathrm{NaBH}_{4}$ or $\mathrm{N}_{2} \mathrm{H}_{4}$ as reduction agents, the use of $\mathrm{H}_{2}$ and $\mathrm{N}_{2}$ gas to reduce copper ions to zerovalent copper decreases the manufacturing expense because the more expensive chemicals are not required. 


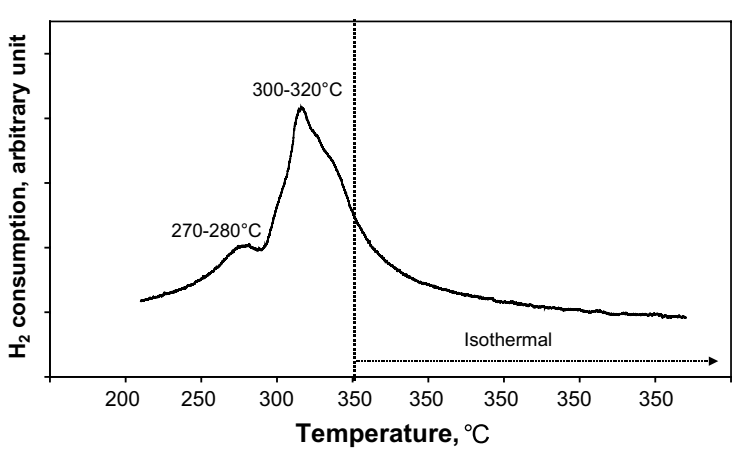

Fig. 2. Consumption of hydrogen during temperature programmed reduction of nanoscale zerovalent copper coated resin. The metal coating was $40 \mathrm{mg}-\mathrm{Cu} / \mathrm{g}$-resin.

\subsection{Characterization of nanoscale zerovalent copper coatings on resin}

Based on transmission electron microscopy, Fig. 4 shows the distribution of $10 \mathrm{mg}$ of zerovalent copper per gram of resin has a size in the range of $5-25 \mathrm{~nm}$. The ion-exchange resin surface as analyzed by EDX was dominant by thionyl, sodium, and carbon. Thus, the resin easily held zerovalent copper in nanoscale patches or particles and did not destroy the ionexchange groups during the process.

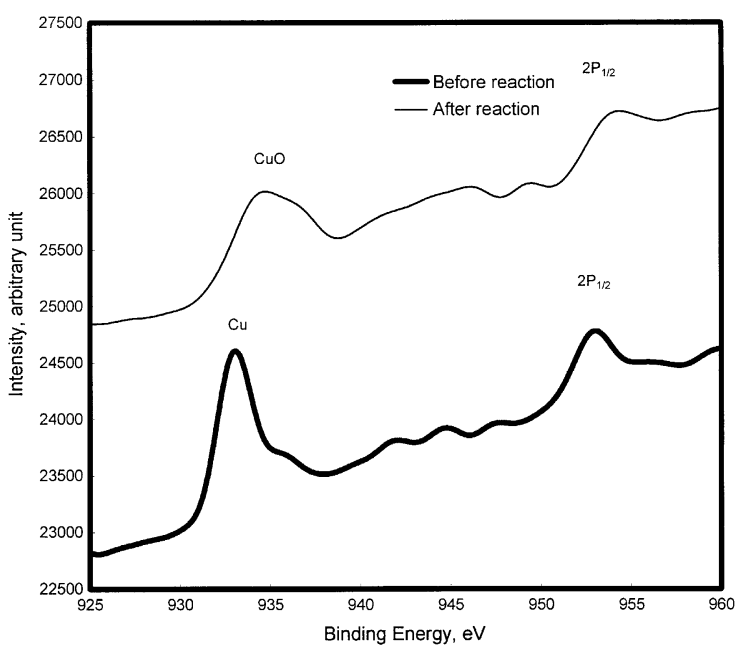

Fig. 3. X-ray photoelectron spectra of the nanoscale zerovalent copper coated resin surface. $\mathrm{Cu}\left(2 \mathrm{p}_{3 / 2}\right): 932.7 \mathrm{eV} ; \mathrm{CuO}\left(2 \mathrm{p}_{3 / 2}\right)$ : $935.0 \mathrm{eV}$.

The effect of heat pretreatment (under a flow of $20 \mathrm{vol} \% \mathrm{H}_{2}$ and $\mathrm{N}_{2}$ gas at $300{ }^{\circ} \mathrm{C}$ for $3 \mathrm{~h}$ ) on the sorption of $\mathrm{Cu}^{2+}$ onto the resin was evaluated using the Langmuir isotherm. Another sample of resin was dried by a vacuum freeze-drying technique $\left(26.8 \mathrm{~Pa}\right.$ and $-55^{\circ} \mathrm{C}$ for 24 h). As shown in Fig. 5(a) and Table 1, the estimated

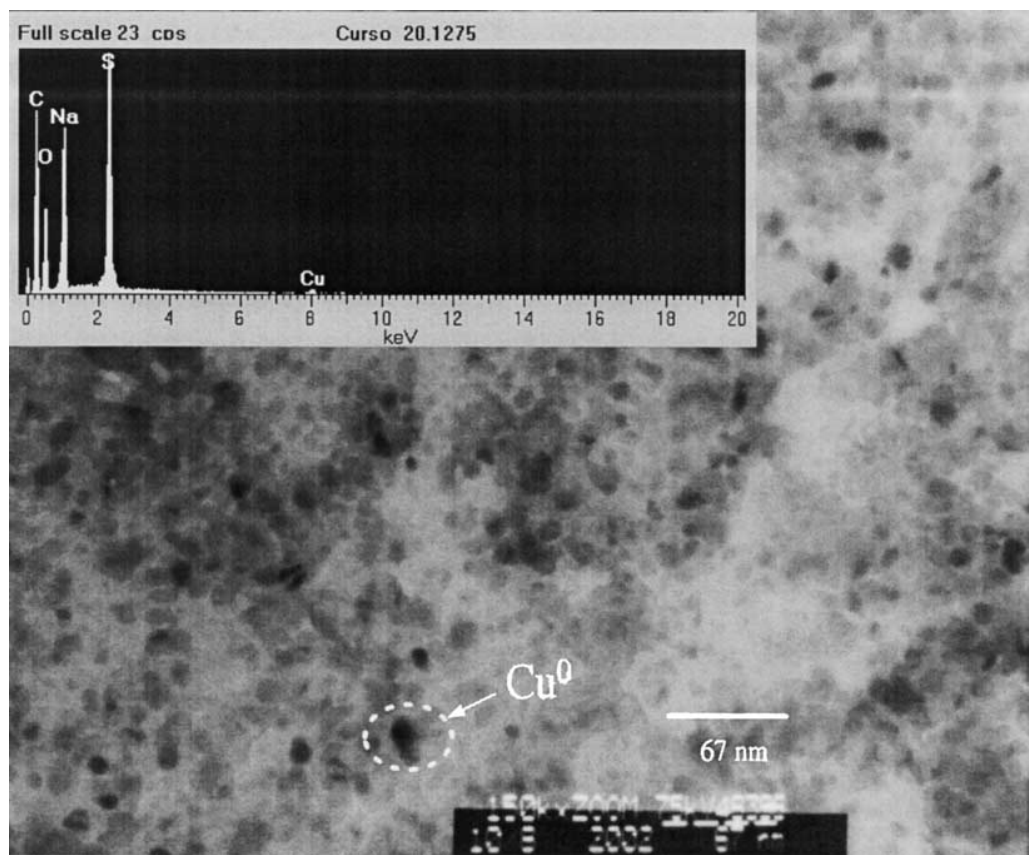

Fig. 4. The TEM image of resin with a coating of $10 \mathrm{mg}$ of zerovalent copper per $\mathrm{g}$ resin. The metallic particles appear as spots with high contrast. The inset EDX graph shows the elements on the surface. 

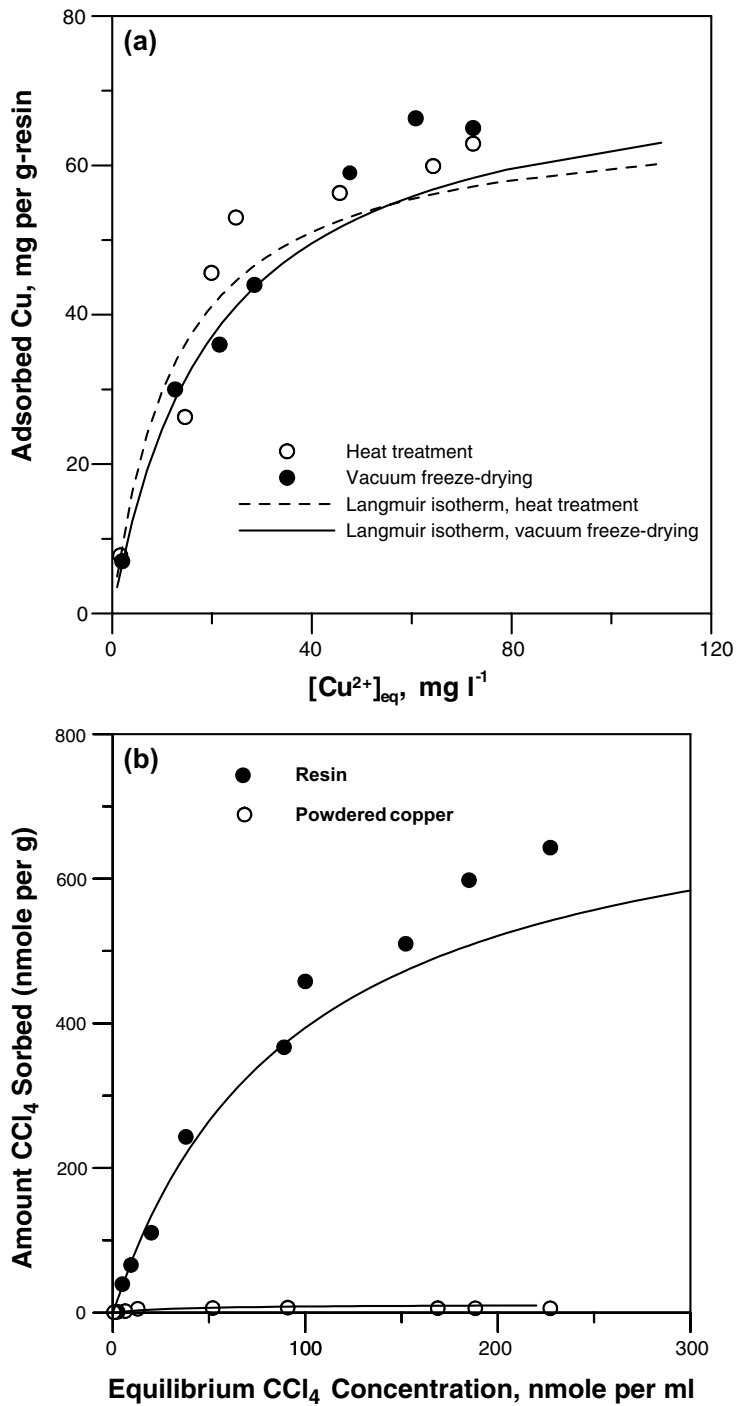

Fig. 5. Sorption isotherms: (a) $\mathrm{Cu}^{2+}$ on the resin pretreated by vacuum freeze-drying and heat pretreatment. (b) $\mathrm{CCl}_{4}$ on the resin and the powdered $\mathrm{Cu}$ particles. Fitted lines are based on the Langmuir equation using the parameters in Table 1.

sorption capacities of Langmuir isotherm for both of the resin with the different pretreatments were $67.6 \pm 10.9 \mathrm{nmol} \mathrm{g}^{-1}$ for heat pretreatment and $79.5 \pm$ $8.9 \mathrm{nmol} \mathrm{g}^{-1}$ for vacuum freeze-drying. The results indicated the ion-exchange capability of the resin after heat pretreatment (a complete reduction procedure) nearly remained intact (the difference of two sorption capacities was not statistically significant with $95 \%$ confidence and 2 degrees of freedom using the independent $t$-test). Elemental analysis with EDX for the resin surface (magnification by 5000 times) revealed typical total copper contents of $1.5-2.0 \%$ (atomic percentage of total elements including carbon, oxygen, sulfur, sodium, and copper) before and after the dechlorination reaction, indicating little dislodging and few copper ions in solution. Therefore, nanoscale zerovalent copper coated resin possessed high mechanical stability in water. After reaction, the copper on the resin was dominantly oxidized into $\mathrm{CuO}$ as identified by ESCA (Fig. 3).

\subsection{Degradation and sorption of carbon tetrachloride using resin coated with nanoscale zerovalent copper}

The disappearance of $\mathrm{CCl}_{4}$ from aqueous solutions may be due to degradation reactions by zerovalent copper or sorption onto the resin. Sorption of $\mathrm{CCl}_{4}$ from solution onto the resin can be described by the Langmuir isotherm (Fig. 5(b)). Table 1 provides that the observed maxima as $11.5 \pm 6.2$ and $770.1 \pm 41.5 \mathrm{nmol} \mathrm{g}^{-1}$ for $\mathrm{CCl}_{4}$ on the powdered copper particles and the resin, respectively. Thus, the sorption of aqueous $\mathrm{CCl}_{4}$ onto the resin dominates sorption onto the zerovalent copper.

A conceptual model of the nanoscale zerovalent copper-resin- $\mathrm{CCl}_{4}$-water system incorporating the degradation reaction by zerovalent copper and sorption and desorption to the resin is similar to that proposed by Burris et al. (1998). The loss of total mass of $\mathrm{CCl}_{4}$ in a closed reactor was fitted with a first-order rate equation of the form

$-\frac{\mathrm{d} C_{\mathrm{T}}}{\mathrm{d} t}=k_{\mathrm{a}} \times C_{\mathrm{w}}=k_{\mathrm{SA}} \times a_{\mathrm{s}} \times \rho_{\mathrm{m}} \times C_{\mathrm{w}}$

where $C_{\mathrm{T}}, C_{\mathrm{w}}$ and $C_{\mathrm{s}}$ are the total, aqueous, and sorbedphase $\mathrm{CCl}_{4}$ concentrations $\mu \mathrm{g} / \mathrm{vial}$, respectively; $t$ is the reaction time (h). $K_{\mathrm{a}}$ is the degradation rate constant $\left(\mathrm{h}^{-1}\right) ; k_{\mathrm{SA}}$ is the surface-area-normalized rate coefficient $\left(1 \mathrm{~h}^{-1} \mathrm{~m}^{-2}\right) ; a_{\mathrm{s}}$ is the specific surface area of metal $\left(\mathrm{m}^{2} \mathrm{~g}^{-1}\right)$; and $\rho_{\mathrm{m}}$ is the mass concentration of the metal $\left(\mathrm{g}^{-1}\right)$. The disappearance rate of aqueous mass with respect to time was due sorption, desorption and degradation reaction.

$-\frac{\mathrm{d} C_{\mathrm{w}}}{\mathrm{d} t}=k_{\mathrm{a}} C_{\mathrm{w}}+\chi_{\mathrm{s}} C_{\mathrm{w}}-\chi_{\mathrm{d}} C_{\mathrm{s}}$

where $\chi_{\mathrm{s}}$ and $\chi_{\mathrm{d}}$ are the soprtion and desorption rate constants, respectively. Despite the sorption onto the zerovalent copper surface, the $\mathrm{CCl}_{4}$ concentrations were measured as aqueous phase in solution and sorbed phase on the resin. Each vial without headspace contained 0.2 or $0.5 \mathrm{~g}$ resin coated with nanoscale zerovalent copper (25 mg-Cu/g-resin), or $0.3 \mathrm{~g}$ commercial powdered copper $(0.04 \mathrm{~mm})$. In separate controls, total concentrations (mass/vial) were stable during the same period. The extraction recoveries for $\mathrm{CCl}_{4}$ from aqueous and sorbed phases in the blank resin vials $(0.2 \mathrm{~g}$-resin/vial) ranged from $91 \%$ to $98 \%$.

Initially, the specific surface area of nanoscale zerovalent copper supported on the resin and for the powdered copper were measured by hydrogen consumption 
Table 1

Fitted Langmuir parameters for sorption of $\mathrm{Cu}^{2+}$ by the resin with different pretreatments (Experiment 1 ) and for sorption of $\mathrm{CCl}_{4}$ by the resin and the powdered copper particles (Experiment 2)

\begin{tabular}{|c|c|c|c|c|c|c|c|c|}
\hline & \multicolumn{4}{|c|}{ Experiment $1: \mathrm{Cu}^{2+}$ sorption } & \multicolumn{4}{|c|}{ Experiment $2: \mathrm{CCl}_{4}$ sorption } \\
\hline & \multicolumn{2}{|c|}{ Heat pretreatment } & \multicolumn{2}{|c|}{$\begin{array}{l}\text { Vacuum freeze- } \\
\text { drying }\end{array}$} & \multicolumn{2}{|l|}{ Resin } & \multicolumn{2}{|c|}{ Powdered $\mathrm{Cu}^{0}$} \\
\hline & (I) & (II) & (I) & (II) & (I) & (II) & (I) & (II) \\
\hline$\overline{S_{m}\left(\mathrm{nmolg}^{-1}\right)}$ & 71.4 & 63.1 & 82.6 & 76.3 & $(770.1)$ & 799.3 & 9.3 & 13.7 \\
\hline$K_{\mathrm{L}}\left(\mathrm{mM}^{-1}\right)$ & \multicolumn{2}{|c|}{$(0.064)$} & 0.047 & $(0.048)$ & \multicolumn{2}{|c|}{$(0.011)$} & 0.035 & $(0.030)$ \\
\hline$r^{2}$ & 0.989 & 0.999 & 0.999 & 0.999 & 0.989 & 0.989 & 0.998 & $(0.996)$ \\
\hline
\end{tabular}

${ }^{a}$ Averaged results from replicate tests were reported.

Table 2

Specific surface areas of resin coated with nanoscale zerovalent copper and powdered copper

\begin{tabular}{lllll}
\hline Sample & $\begin{array}{l}\text { Mass of } \\
\text { sample } \\
(\mathrm{g})\end{array}$ & $\begin{array}{l}\mathrm{H}_{2} \text { consumption } \\
(\mathrm{nmol} / \mathrm{g} \text {-sample })\end{array}$ & $\begin{array}{l}\text { Copper surface } \\
\text { area, } S_{\mathrm{Cu}} \\
\left(\mathrm{m}^{2}-\mathrm{Cu} / \mathrm{g}-\mathrm{resin}\right)\end{array}$ & $\begin{array}{l}\text { Copper surface } \\
\mathrm{area}, S_{\mathrm{Cu}} \\
\left(\mathrm{m}^{2}-\mathrm{Cu} / \mathrm{g}-\mathrm{Cu}\right)\end{array}$ \\
\hline $25 \mathrm{mg}-\mathrm{Cu}^{0} / \mathrm{g}$-resin & 0.20 & $13.0 \pm 0.1$ & $1.12 \pm 0.02$ & $44.8 \pm 0.08$ \\
${\text { Powdered } \mathrm{Cu}^{0}}$ & 0.30 & $23.9 \pm 0.3$ & - & $2.05 \pm 0.04$ \\
\hline
\end{tabular}

during temperature programmed reduction. The values are shown in Table 2. The surface area of nanoscale zerovalent copper is approximately 22 times that of powdered copper.

As shown in Fig. 6(a) and (b), complete degradation of $\mathrm{CCl}_{4}$ in 0.2 and $0.5 \mathrm{~g}$ nanoscale zerovalent copper coated resin per vial took about $16-17 \mathrm{~h}$ and $5-6 \mathrm{~h}$, respectively. The observed degradation rates $\left(k_{\mathrm{obs}}\right)$ were $0.24 \pm 0.02 \mathrm{~h}^{-1}$ for $0.2 \mathrm{~g}$ nanoscale zerovalent copper coated resin per vial and $0.80 \pm 0.03 \mathrm{~h}^{-1}$ for $0.5 \mathrm{~g}$ nanoscale zerovalent copper coated resin per vial and then normalized with the specific surface area (1.12 \pm $0.02 \mathrm{~m}^{2} \mathrm{Cu} / \mathrm{g}$-resin) and the mass concentration of nanoscale zerovalent copper coated resin $\left(13.3 \mathrm{~g} \mathrm{l}^{-1}\right)$ to $k_{\mathrm{SA}}$, $0.016 \pm 0.002$ and $0.021 \pm 0.001 \mathrm{~h} \mathrm{~h}^{-1} \mathrm{~m}^{-2}$, respectively. The $k_{\text {obs }}$ and $k_{\mathrm{SA}}$ for powdered copper were $0.028 \pm 0.004 \mathrm{~h}^{-1}$ and $0.0010 \pm 0.0001 \mathrm{~h} \mathrm{~h}^{-1} \mathrm{~m}^{-2}$, respectively. Reducing the size of copper particles to a nanoscale would sharply increase $k_{\mathrm{SA}}$ by a factor of about 24. Other experiments $(0.5 \mathrm{~g}$ zerovalent copper coated resin per vial) revealed that the $k_{\text {obs }}$ for nanoscale zero valent copper coated resin submerged continuously in Ar-purged Milli-Q water for $7 \mathrm{~d}$ was $0.73 \pm 0.004 \mathrm{~h}^{-1}$. Then, the same nanoscale zerovalent copper coated resin was regenerated by $\mathrm{H}_{2}$ at $300{ }^{\circ} \mathrm{C}$ for $3 \mathrm{~h}$, increasing the $k_{\mathrm{obs}}$ to $0.85 \pm 0.003 \mathrm{~h}^{-1}$. Thus the reactivity of nanoscale zerovalent copper coated resin was decreased in the long-term reaction, but was restored by $\mathrm{H}_{2}$ treatment (95\% confidence and 4 degrees of freedom using the independent $t$-test).
The sorption and desorption rate constants $\chi_{\mathrm{s}}$ and $\chi_{\mathrm{d}}$ were estimated by fitting the observed aqueous $\mathrm{CCl}_{4}$ concentration $C_{\mathrm{w}}$ with the exact solution of Eq. (7) derived by Burris et al. (1998). The sorption and desorption rate constants $\chi_{\mathrm{s}}$ and $\chi_{\mathrm{d}}$ were respectively $0.21 \pm 0.002$ and $0.28 \pm 0.002 \mathrm{~h}^{-1}$ for $0.2 \mathrm{~g}$ nanoscale zerovalent copper coated resin per vial; these were $0.41 \pm 0.03$ and $0.30 \pm 0.03 \mathrm{~h}^{-1}$ for $0.5 \mathrm{~g}$ nanoscale zerovalent copper coated resin per via. Increasing nanoscale zerovalent copper coated resin loading per vial increased the sorption rate constant but not the desorption rate constant. As shown in Fig. 6, the initial $C_{\mathrm{w}}$ data were matched by the estimated values of the exact solution with values of constant $\chi_{\mathrm{s}}$ and $\chi_{\mathrm{d}}$ (within 7 and $2 \mathrm{~h}$, respectively). The apparent differences between the observed and estimated data in the final period of reaction implies the desorption rate may be not first-order (the estimated deposition rate is slower than the actual rate).

\subsection{Residual copper ions concentration and $p H$}

The residual copper ions in the effluent are the product of the reaction between $\mathrm{CCl}_{4}$ and $\mathrm{Cu}^{0}$. These are considered to be hazardous species and the concentrations must be reduced below those required by effluent standards. Fig. 7 shows the residual copper ions concentration and the $\mathrm{pH}$ of both commercial powdered copper and nanoscale zerovalent copper coated resin. For a powdered $\mathrm{Cu}-\mathrm{CCl}_{4}-\mathrm{H}_{2} \mathrm{O}$ system, the residual copper ions exceeded $1.0 \mathrm{mg} \mathrm{l}^{-1}$, falling to $0.6 \mathrm{mg} \mathrm{l}^{-1}$ for a long 

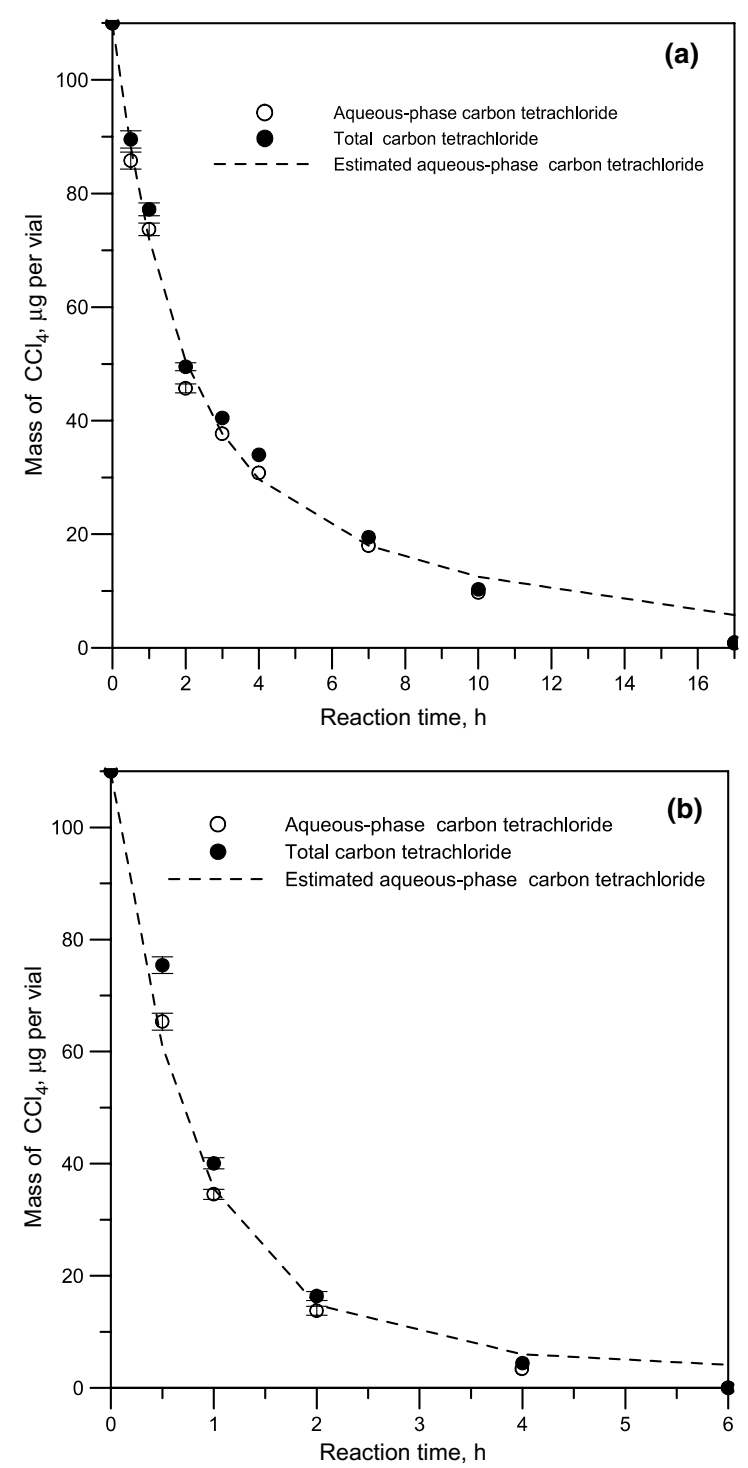

Fig. 6. Disappearance of $\mathrm{CCl}_{4}$ with $95 \%$ confidence interval in a well-mixed batch system ( $15 \mathrm{ml}$ vial with no headspace). (a) $0.2 \mathrm{~g}$ nanoscale zerovalent copper coated resin, $\chi_{\mathrm{s}}: 0.21 \pm$ $0.02 \mathrm{~h}^{-1}, \chi_{\mathrm{d}}: 0.28 \pm 0.02 \mathrm{~h}^{-1}$. (b) $0.5 \mathrm{~g}$ nanoscale zero valent copper coated resin, $\chi_{\mathrm{s}}: 0.41 \pm 0.03 \mathrm{~h}^{-1}, \chi_{\mathrm{d}}: 0.30 \pm 0.03 \mathrm{~h}^{-1}$.

period, due to the precipitation of metal carbonate or oxide (Fig. 3 shows the build up of $\mathrm{CuO}$ ). However, these concentrations are typically under $0.1 \mathrm{mg} \mathrm{l}^{-1}$ and the $\mathrm{pH}$ dropped to $3-4$ in nanoscale zerovalent copper coated resin system. The difference in copper ion concentration in aqueous solution between copper powder and nanoscale zerovalent copper coated resin results from the ion exchange of the resin as a support. On the nanoscale zerovalent copper coated resin, when zerovalent copper is oxidized into copper ion, $\mathrm{H}^{+}$or $\mathrm{Na}^{+}$are re-

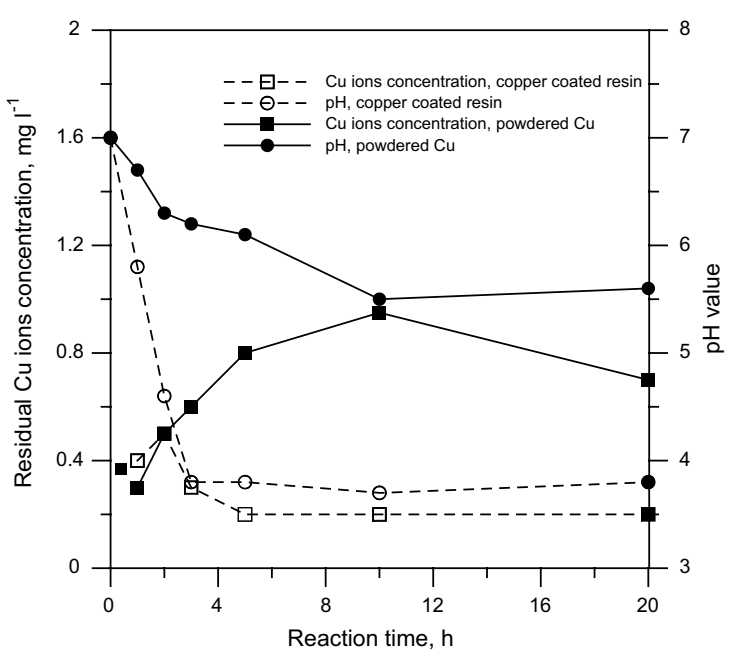

Fig. 7. Residual copper ion concentration and $\mathrm{pH}$ in a wellmixed batch system.

leased from the resin to exchange copper ion. Thus, the use of the resin as a support not only removes copper ions from the solution but also drops $\mathrm{pH}$ to acidic conditions.

The possible copper contamination resulting from the displacement by other multivalent cations present in groundwater limits the potential in situ application of nanoscale zerovalent copper coated resin. This competition depends on the composition of groundwater is inevitable and mainly causes the decrease in copper recovery over time. Considering metal toxicity and the required reduction temperature of metal ions, alternative metals like tin may to be more applicable in situ.

\section{Conclusions}

Nanoscale zerovalent copper coated resin, synthesized in a flow of $\mathrm{H}_{2}$ and $\mathrm{N}_{2}$ gas $\left(20 \mathrm{vol} \%, 50 \mathrm{ml} \mathrm{min}^{-1}\right)$ at $300{ }^{\circ} \mathrm{C}$ for $3 \mathrm{~h}$, is an efficient and mechanically stable reductant for the degradation of $\mathrm{CCl}_{4}$ in water. Reducing the size of the copper particles to a nanoscale increases the reactivity by a factor of about 24 . The use of the cation-resin as a support decreases the copper ions in the effluent at a concentration of less $0.1 \mathrm{mg} / 1$ and simultaneously maintains the solution $\mathrm{pH}$ at 3-4. Over the long term, this reductant can be restored to reactivity by $\mathrm{H}_{2}$. Thus, advantages of the application of nanoscale zerovalent copper coated resin as reductive material to degrade chlorinated solvents can be attributed to (1) the increase in the rate constant due to the nanosize of metal particles; (2) the combined effect of degradation and sorption; (3) the acid $\mathrm{pH}$ range during the dechlorination process; (4) the recycling of metal ions in the solution. In the above-ground application, this reduc- 
tant would facilitate the development of a process that could be designed for convenient emplacement and regeneration of porous reductive medium. In situ, metal coated resin may not be as useful until the effects of competitive ions in local groundwater can be related to the release of toxic metals.

\section{Acknowledgement}

The authors would like to thank the National Science Council of the Republic of China for financially supporting this research under Contract No. NSC 922211-E-002-063.

\section{References}

Agrawal, A., Tratnyek, P.G., 1996. Reduction of nitro aromatic compounds by zero-valent iron metal. Environ. Sci. Technol. 30, 153-160.

Bond, G.C., Namijo, S.N., 1989. An improved procedure for estimating the metal surface area of supported copper catalysts. J. Catal. 118, 511-512.

Boronina, T., Klabunde, K.J., Sergeev, G.B., 1995. Destruction of organohalides in water using metal particles: carbon tetrachloride/water reaction with magnesium, tin, and zinc. Environ. Sci. Technol. 29, 1511-1517.

Burris, D.R., Campbell, T.J., Manoranjan, V.S., 1995. Sorption of trichloroethylene and tetrachloroethylene in a batch reactive metallic iron-water system. Environ. Sci. Technol. 29, 2850-2855.

Burris, D.R., Allen-King, R.M., Manoranjan, V.S., Campbell, T.J., Loraine, G.A., Deng, B., 1998. Chlorinated ethene reduction by cast iron: sorption and mass transfer. J. Environ. Eng., 1012-1019.

Chen, J.L., Al-Abed, S.R., Ryan, J.A., Li, Z., 2001. Effects of $\mathrm{pH}$ on dechlorination of trichloroethylene by zero-valent iron. J. Hazard. Mater. B 83, 243-254.

Cheng, S.F., Wu, S.C., 2000. The enhancement methods for the degradation of TCE by zero-valent metals. Chemosphere 41, 1263-1270.

Choe, S., Chang, Y.Y., Hwang, K.Y., Khim, J., 2000. Kinetic of reductive denitrification by nanoscale zero-valent iron. Chemosphere 41, 1307-1311.

Doong, R.A., Chen, K.T., Tsai, H.C., 2003. Reductive dechlorination of carbon tetrachloride and tetrachloroethylene by zerovalent silicon-iron reductants. Environ. Sci. Technol. 37, 2575-2581.

Evans, J.W., Wainwright, M.S., Bridgewater, A.J., Young, D.J., 1983. On the determination of copper surface area by reaction with nitrous oxide. Appl. Catal. 7, 75-83.

Eykholt, G.R., Davenport, D.T., 1998. Dechlorination of the chloroacetanilide herbicides alachlor and metolachlor by iron metal. Environ. Sci. Technol. 32, 1482-1487.

Gillham, R.W., O’Hannesin, S.F., 1994. Enhanced degradation of halogenated aliphatics by zero-valent iron. Ground Water 32, 958-967.
Grift, C.J.G., Wielers, A.F.H., Joghi, B.P.J., Beijnum, J., Boer, M., Versluus-Helder, M., Gues, J.W.J., 1991. Effect of the reduction treatment on the structure and reactivity of silicasupported copper particles. Catal. 131, 178-189.

Gu, B., Phelps, T.J., Liang, L., Dickey, M.J., Ron, Y., Kinsall, B.L., Palumbo, A.V., Jacobs, G.K., 1999. Biogeochemical dynamics in zerovalent iron columns: Implications for permeable reductive barriers. Environ. Sci. Technol. 33, 2170-2177.

Huang, C.P., Wang, H.W., Chiu, P.C., 1998. Nitrate reduction by metallic iron. Wat. Res. 32, 2257-2264.

Klabunde, K.J., 2001. Nanoscale Materials in Chemistry. Wiley, New York, p. 11.

Kim, Y.H., Carraway, E.R., 2000. Dechlorination of pentachlorophenol by zerovalent iron and modified zero valent irons. Environ. Sci. Technol. 34, 2014-2017.

Matheson, L.J., Tratnydk, P.G., 1994. Reductive dehalogenation of chlorinated methanes by iron metal. Environ. Sci. Technol. 28, 2045-2053.

McCutcheon, S.C., Schnoor, J.L., 2003. Phytoremediation: Transformation and Control of Contaminants. Wiley, New York, p. 1-10.

Muftikian, R., Fernando, Q., Korte, N., 1995. A method for rapid dechlorination of low molecular weight chlorinated hydrocarbons in water. Wat. Res. 29, 2434-2439.

Nam, S., Tratnyek, P.G., 2000. Reduction of azo dyes with zero-valent iron. Wat. Res. 34, 1837-1845.

Orth, W.S., Gillham, R.W., 1996. Dechlorination of trichloroethene in aqueous solution using $\mathrm{Fe}^{0}$. Environ. Sci. Technol. 30, 66-71.

Phillips, D.H., Gu, B., Watson, D.B., Roh, Y., Liang, L., Lee, S.Y., 2000. Performance evaluation of a zerovalent iron reactive barrier: mineralogical characteristics. Environ. Sci. Technol. 34, 4169-4176.

Sayles, G.D., You, G., Wang, M., Kupferle, M.J., 1997. DDT, DDD, and DDE dechlorination by zero-valent iron. Environ. Sci. Technol. 31, 3448-3454.

Siantar, D.P., Schreier, C.G., Chou, C.S., Reinhard, M., 1996. Treatment of 1,2-dibromo-3-chloropropane and nitratecontaminated water with zero-valent iron or hydrogen/ palladium catalysts. Wat. Res. 30, 2315-2322.

Su, C., Puls, R.W., 1999. Kinetics of trichloroethene reduction by zerovalent iron and tin: pretreatment effect, apparent activation energy, and intermediate products. Environ. Sci. Technol. 33, 163-168.

Su, C., Puls, R.W., 2004. Nitrate reduction by zerovalent iron: effects of formate, oxalate, citrate, chloride, sulfate, borate, and phosphate. Environ. Sci. Technol. 38, 27152720 .

Wang, C.B., Zhang, W.X., 1997. Synthesizing nanoscale iron particles for rapid and complete dechlorination of TCE and PCBs. Environ. Sci. Technol. 31, 2154-2156.

Zhang, W.X., Wang, C.B., Lien, H.L., 1998. Treatment of chlorinated organic contaminants with nanoscale bimetallic particles. Catal. Today 40, 387-395.

Ziolo, R.F., Giannelis, E.P., Weinstein, B.A., O'Horo, M.P., Ganguly, B.N., Mehrotra, V., Russell, M.W., Huffman, D.R., 1992. Matrix-mediated synthesis of nanocrystalline $\gamma$ $\mathrm{Fe}_{2} \mathrm{O}_{3}$ : a new optically transparent magnetic material. Science 257, 219-222. 